\title{
Elucidating changes in the degree of tracer dispersion in a subglacial channel
}

\author{
Thomas SCHULER, Urs H. FISCHER \\ Versuchsanstalt für Wasserbau, Hydrologie und Glaciologie, Eidgenössische Technische Hochschule, ETH-Zentrum, Gloriastrasse 37/39, \\ CH-8092 Zürich, Switzerland \\ E-mail: schuler@vaw.baug.ethz.ch
}

\begin{abstract}
Tracer injections into a subglacial channel at Unteraargletscher, Switzerland, were repeated at intervals of about 2 hours over two diurnal discharge cycles in August and September 2000. Records of dye concentration reveal a pronounced hysteresis in the velocity-dispersion relationship, thereby indicating alterations in the drainage system. Theoretical considerations for Röthlisberger channels suggest an evolution of the conduit cross-section in response to a diurnally varying discharge. We studied the relation between conduit cross-section and tracer dispersion with numerical tracer experiments. The velocity field for steady flow through a given conduit geometry is calculated using a commercial flow solver. Tracer transport is represented by a scalar volume which is advected by the velocity field. Experiments were conducted for several scenarios by varying flow velocity, conduit geometry and conduit roughness. Results show only a weak dependence of dispersion on conduit size. In contrast, changes in roughness of the conduit walls reveal a strong effect on tracer dispersion. Therefore, to explain the observed hysteresis in the velocity-dispersion relationship, we suggest that the evolution of a subglacial flow path might involve changes in roughness.
\end{abstract}

\section{INTRODUGTION}

Tracer techniques are powerful tools for investigating virtually inaccessible hydrological systems and processes. In such investigations, the transit velocity of a tracer through the drainage system and the shape of the tracer breakthrough curve (TBC) are the most commonly evaluated transport parameters. These parameters are governed by both water discharge through and the structure of the drainage system. A characteristic feature of discharge through a glacier is its pronounced variability on seasonal and diurnal time-scales. In addition, a glacial drainage system has the ability to adjust its geometry to prevailing hydraulic conditions. The structure of glacial drainage systems and their evolution with time can be characterized by performing tracer tests over a range of different discharges to investigate the variations of transit velocity and tracer dispersion with discharge (Collins, 1982; Seaberg and others, 1988; Fountain, 1993; Hock and Hooke, 1993; Kohler, 1995; Nienow and others, 1996). In this paper, we focus on the investigation of the instantaneous structure of a subglacial flow path at Unteraargletscher, a temperate valley glacier in the Bernese Alps, Switzerland. We present results from series of tracer tests which were conducted in quick succession over two diurnal discharge cycles during the ablation season 2000 to assess the variability of transport parameters on a time-scale of 1 day.

\section{OBSERVATIONS}

Over two diurnal discharge cycles in August and September 2000 , injections of sulforhodamine B into a moulin near the central flowline approximately $4.5 \mathrm{~km}$ up-glacier from the terminus were repeated at intervals of about 2 hours and were accompanied by simultaneous measurements of discharge in the proglacial stream. Figure 1 shows the concentration time series recorded in the proglacial stream which resulted from these injections. Both series yielded sets of easily separable and independent TBC.s. The individual TBCs were analyzed using a simple advection-dispersion model (ADM). For an instantaneous input of a tracer mass $m$ (kg), the one-dimensional analytical solution for the tracer concentration $c\left(\mathrm{~kg} \mathrm{~m}^{-3}\right)$ at a distance $x(\mathrm{~m})$ from the injection point (Kreft and Zuber, 1978) is given by

$$
c(t)=\frac{m}{Q} \frac{x}{\left(4 \pi D t^{3}\right)^{\frac{1}{2}}} \exp \left[-\frac{(x-v t)^{2}}{4 D t}\right]
$$

where $Q\left(\mathrm{~m}^{3} \mathrm{~s}^{-1}\right)$ is the discharge, assumed to be steady, and $t$ (s) denotes time. The transport parameters velocity $v\left(\mathrm{~m} \mathrm{~s}^{-1}\right)$ and the dispersion coefficient $D\left(\mathrm{~m}^{2} \mathrm{~s}^{-1}\right)$ are then determined by fitting the model to the rising limb of the TBC such that the peak concentration is conserved (Sauty and Kinzelbach, 1988). If the tracer transport is affected by storage retardation processes (e.g. Willis and others, 1990; Fountain, 1993), the ADM can account only partly for the declining limb of the TBC. In this case, the difference of the area under the calculated and the measured curve is used to express storage retardation (Hauns and others, 2001).

Figures 2 and 3 show the derived transport parameters for the experiments in August and September, respectively. Also shown are the bulk discharges in the proglacial stream averaged over the duration of each individual tracer breakthrough. Note that due to the unequal time intervals 

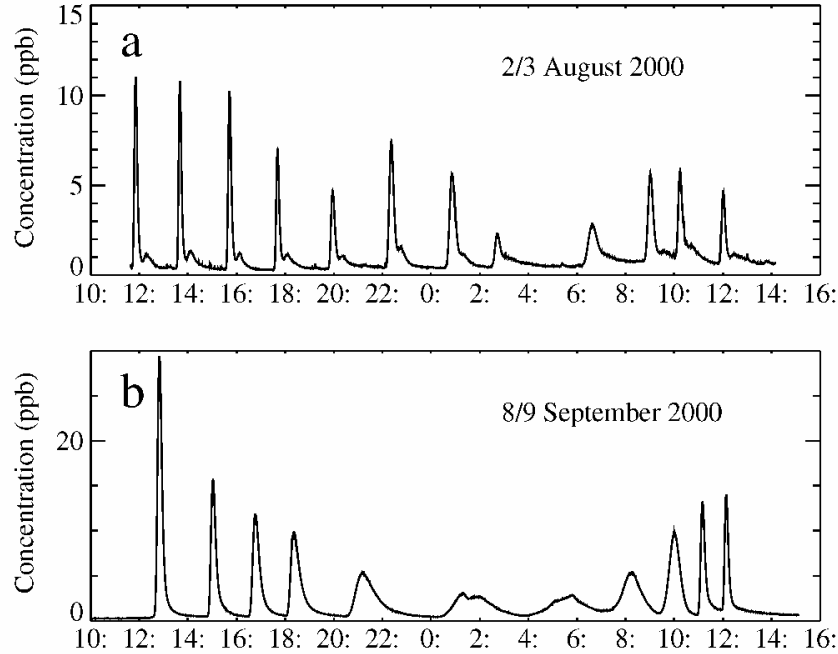

Fig. 1. Time series of tracer concentration in the proglacial stream of Unteraargletscher, resulting from injections of sulforhodamine B into a moulin $\sim 4.5 \mathrm{~km}$ from the glacier terminus. Each experiment covers an entire diurnal cycle in August (a) and September 2000 ( b ).
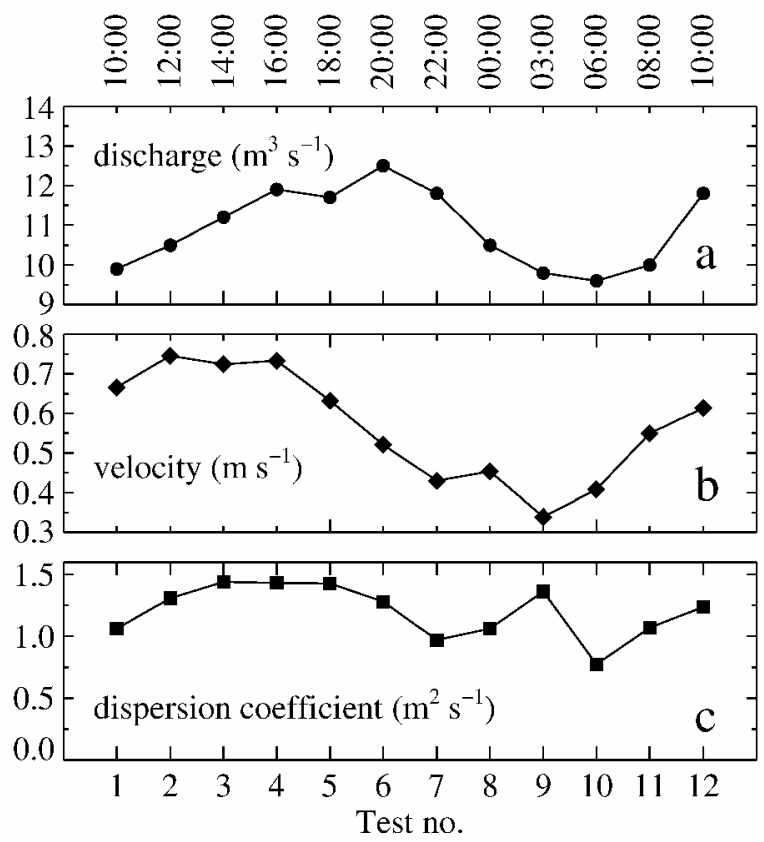

Fig. 2. Results of repeated tracer injections over one diurnal discharge cycle in August 2000. (a) Bulk discharge in the proglacial stream averaged over the duration of tracer breakthrough. Transitvelocities ( $b$ ) and dispersion coefficients (c) are derived from fitting the ADM to individual TBCs. The horizontal axis on top refers to the time of tracer injections.

between injections, the horizontal axes cannot be directly translated into time axes.

The transit velocity during the experiment in August varies between 0.34 and $0.75 \mathrm{~m} \mathrm{~s}^{-1}$. In addition, the velocity variation precedes that of bulk discharge in phase such that the velocity at the rising limb of discharge is higher than that at the falling limb (Fig. 2). During the September experiment, the course of discharge is characterized by an increasing trend superimposed on a diurnal variation (Fig. 3). We surmise that this increase is due to an increase in meltwater input to the glacier with the return of sunny and warm-

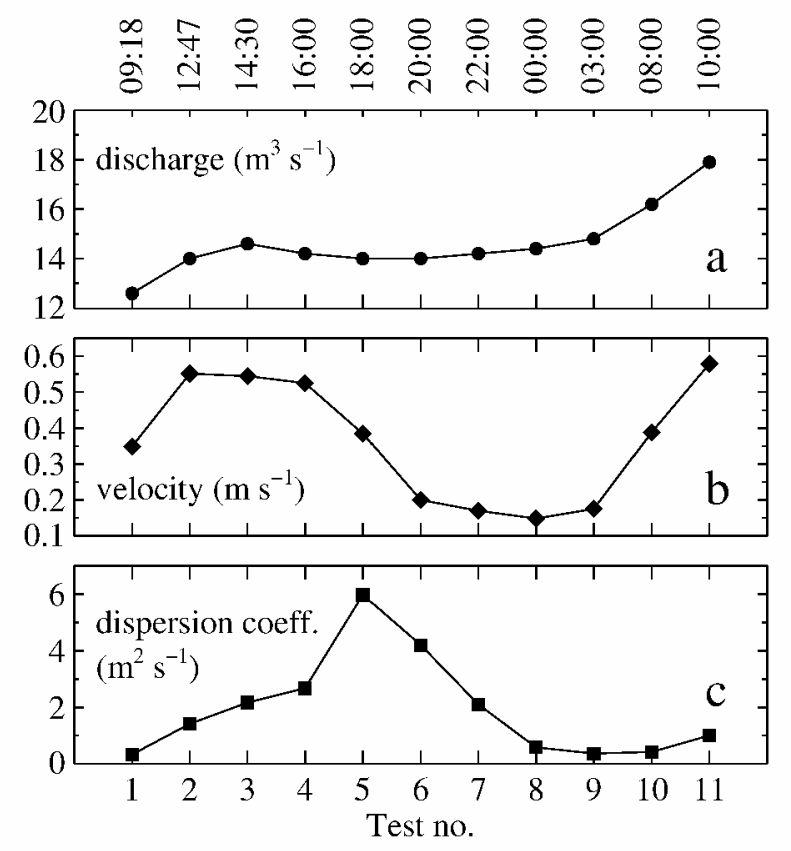

Fig. 3. Same as Figure 2, but for September 2000.

\section{August}

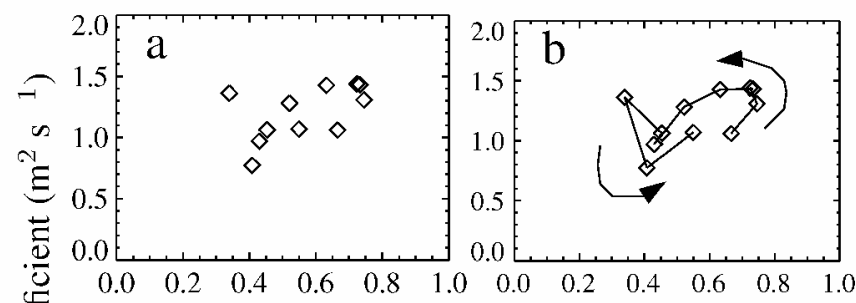

\section{September}

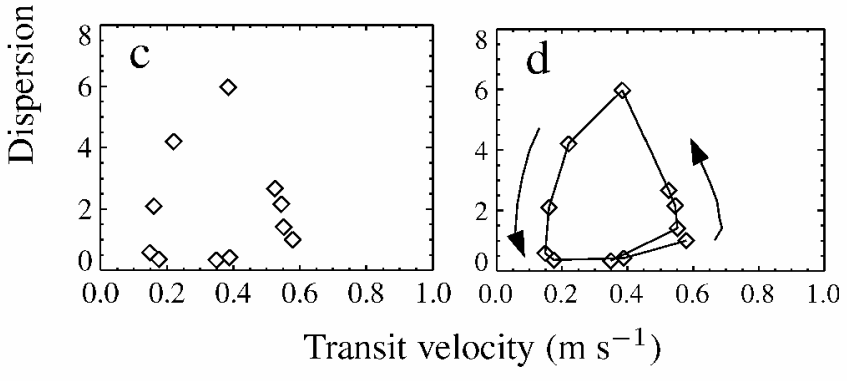

Fig. 4. Velocity-dispersion relationships derived from the tracer tests in August $(a, b)$ and September $(c, d)$. The arrows indicate the chronological order.

weather after a cold period. Despite the increasing trend in discharge, the transit velocity shows a diurnal variation similar to that in August.

The accuracy of the transport parameters $v$ and $D$ depends primarily on the degree to which the time of the tracer breakthrough can be determined. As a conservative estimate of this error, we assign an uncertainty of $\pm 1 \mathrm{~min}$. With peak concentrations of the fastest TBCs occurring about $100 \mathrm{~min}$ after tracer injection, this uncertainty translates into inaccuracies $\leq 1 \%$ for both $v$ and $D$. These inaccuracies are smaller than the size of the symbols plotted for each data point in Figures 2 and 3.

The observed fast transit velocities of the tracer through the glacier (Figs 2 and 3) in conjunction with the reappearance of the tracer at the glacier portal in narrow 
TBCs (Fig. 1) suggest water flow through a channelized drainage system. For a given conduit with constant roughness and diameter, it has been found that $D$ is approximately proportional to $v$ (Taylor, 1954). Investigations of the $v-D$ relationship have been used to infer the dispersive behavior of subglacial flow paths from the slope of a linear regression of $v$ on $D$ (e.g. Seaberg and others, 1988).

Figure 4 illustrates the observed relationships between transit velocity and dispersion coefficients for the August and September experiments. The significant scattering in both $v-D$ relationships (Fig. $4 \mathrm{a}$ and c) inhibits the determination of a linear functional relationship. In fact, if the chronological order of the data is taken into account (Fig. 4b and d), the $v-D$ relationships reveal hystereses in anticlockwise direction such that the dispersion coefficients are systematically higher during declining than during increasing velocity.

\section{INTERPRETATION}

Röthlisberger (1972) postulated conduits with a dynamic geometry which is controlled by the counteracting processes of melt enlargement due to dissipation of potential energy of the flowing water vs creep closure of the viscous ice. While Röthlisberger (1972) considered the steady state, Spring and Hutter (1982) investigated the time-dependent behavior of such conduits. It was found that in response to a diurnally varying discharge, the conduit diameter evolves such that it is larger during declining than during rising discharge. This in turn causes the velocity to be higher at the rising as compared to the declining limb of the discharge variation.

Such behavior is indicated by the observed variations of discharge and transit velocity as illustrated in Figure 2, whereas in response to a continuously increasing discharge, the conduit presumably grows steadily. In this case (Fig. 3), low discharge during the night would cause a pronounced velocity depression (Schuler, 2002).

Based on this interdependence of discharge, conduit size and flow velocity for a dynamic Röthlisberger conduit, we suggest a positive relationship between conduit size and dispersion coefficient to explain the observed hysteresis in the $v-D$ relationship (Fig. 3).

\section{Tracer transport simulation}

To test the hypothesis stated above, numerical tracer tests were performed to study systematically the influence of changes of conduit geometry on tracer dispersion. Therefore, a model is adopted which was used by Hauns and others (1998) and Hauns (1999) to investigate the retardation of water flow in karst conduits. The approach consists in describing the three-dimensional velocity field of turbulent discharge through a given geometry. Subsequently, tracer transit is simulated by a scalar volume which is propagated through this flow field by advection. Hauns and others (1998) have validated the model with laboratory experiments. In this study, we apply this model to several idealized conduits which differ in size, shape and roughness. For each conduit scenario, TBCs were generated for different hydraulic conditions.

\section{Model description}

The Navier-Stokes equations are solved with a $k-\varepsilon-$ turbulence model (e.g. Harlow and Nakayama, 1967; Launder

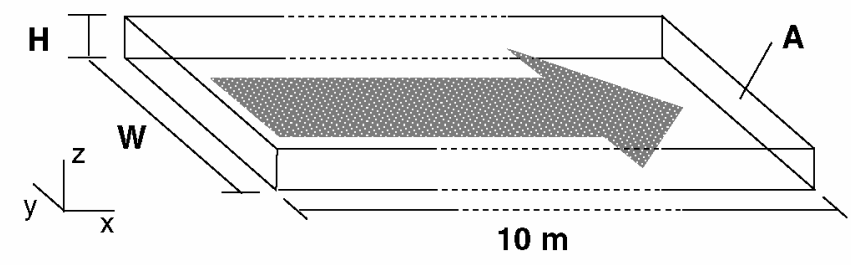

\section{Fig. 5. The idealized conduit geometry through which numerical tracer tests were performed. Water flow is in x direction.}

and Spalding, 1974) using the finite-volume method. We used the commercial package CFX-4.3 of AEA Technology, which provides a complete software environment to solve turbulent flow problems. In our study, the three-dimensional velocity field was computed for an idealized conduit which was represented by a $10 \mathrm{~m}$ long rectangular geometry (Fig. 5). Along the conduit walls, a no-slip condition is applied. The amount and direction of water discharge is controlled by prescribing a constant velocity at the inlet and a no-pressure condition at the outlet plane.

In the turbulent velocity field, transport of a conservative tracer is then simulated by advection of a scalar representing the tracer concentration. As such, the approach is valid only if the tracer's influence on the fluid density is negligible. This is typically the case in the experiments at Unteraargletscher where maximum observed tracer concentrations were $<30$ ppm (Fig. 1).

Tracer injection is simulated by applying a constant scalar flux over a $2 \mathrm{~s}$ interval at the conduit inlet. After transport of the tracer through the conduit, the scalar field is sampled at the outlet, and its time series is analogous to a TBC.

Explicit computation of the flow field and simulation of the tracer transport is restricted to idealized conduits at the $10^{1} \mathrm{~m}$ length scale because at larger length scales the computational effort becomes excessive. However, tracer tests in the field are typically performed over length scales of $10^{2}-10^{3} \mathrm{~m}$. Therefore, to examine tracer transport in conduits at the scale of hundreds of meters, we used the transfer function approach (Hauns and others, 2001) to expand the model to the $10^{2} \mathrm{~m}$ length scale. This approach entails that once the

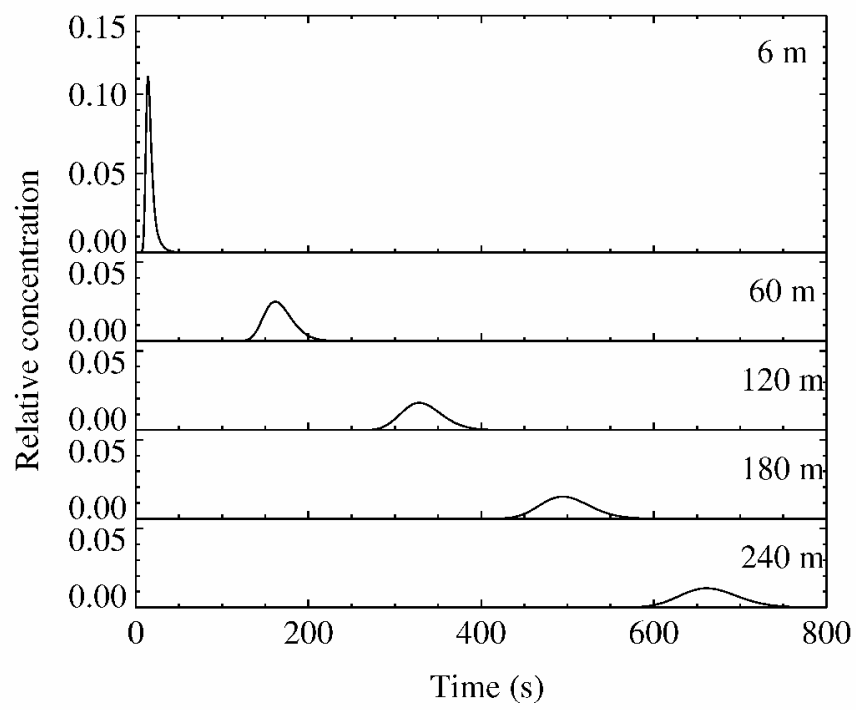

Fig. 6. The evolution of TBCs along the conduit with increasing distance from the injection point (6, 60, 120, 180 and $240 \mathrm{~m}$ ). Tracer concentration is shown relative to its input value. 


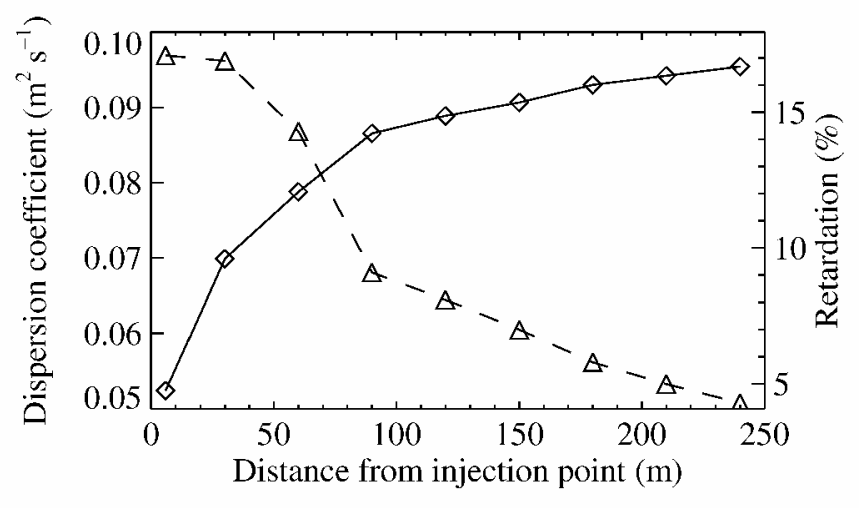

Fig. 7. The evolution of dispersion coefficient (solid line) and retardation (dashed line) of the TBCs shown in Figure 4 with increasing distance from the injection point. Retardation is quantified by the portion of the tracer mass, which is not accounted for by the ADM.

transfer function of a $10^{1} \mathrm{~m}$ length-scale conduit is obtained using the numerical model, simulations of tracer transport in conduits of any desired length can be generated by concatenation of such transfer functions (Box and others, 1994).

In this study, the transfer function approach was used for upscaling a $10 \mathrm{~m}$ long conduit (Fig. 5) to a length of $240 \mathrm{~m}$. Figure 6 illustrates how the shape of a return curve evolves with increasing distance from the injection point at the conduit inlet. Tracer concentration was logged at several distances along the conduit. The first breakthrough curve displays an asymmetrical shape which is characterized by a fast rise and a slow decline, indicative of pronounced retardation. With increasing distance, the asymmetry of the return curves decreases gradually, peak concentrations decline and curves become broader. This evolution was quantified using the $\mathrm{ADM}$ as described above. Figure 7 shows how the dispersion coefficient increases with distance to the injection-point length concurrent with a decrease of retardation. This observation is in agreement with findings of Hauns and others (2001) and demonstrates how tracer retardation at small scales contributes to hydraulic dispersion at larger spatial scales.

\section{Numerical experiments}

The influence on tracer dispersion was systematically studied by altering the size, shape and roughness of the conduit. To characterize the dispersive behavior, we derived velocity-dispersion relationships for each of these scenarios by using a number of different flow velocities.

In a first set of experiments, the height $H$ of the conduit geometry was varied to generate conduits with different cross-sectional areas $A$. Table 1 lists details of individual experiments.

Since the flow velocity is zero at the conduit walls, the flow field and therefore also the tracer transport is affected by the fraction of water volume that is in contact with the wall. This influence can be examined by systematically varying the hydraulic radius $R_{\mathrm{h}}=A / U$, where $A$ is the cross-sectional area that is occupied by the water and $U$ is the wetted perimeter of the conduit. In a second set of experiments, we studied this effect using four conduits with different cross-sectional shapes while keeping $A=0.25 \mathrm{~m}^{2}$ constant (Table 2). In each case, a mean flow velocity $v_{\text {in }}=0.3 \mathrm{~m} \mathrm{~s}^{-1}$ was applied.

In a final set of experiments, TBCs were generated to investigate the effect of roughness on tracer dispersion. In
Table 1. Height $H$, width $W$ and cross-sectional area $A$ of different conduits used to study the effect of conduit size on tracer dispersion. $v_{\text {in }}$ is the mean flow velocity

\begin{tabular}{cccc}
\hline$v_{\text {in }}$ & $H$ & $W$ & $A$ \\
$\mathrm{~m} \mathrm{~s}^{-1}$ & $\mathrm{~m}$ & $\mathrm{~m}$ & $\mathrm{~m}^{2}$ \\
\hline 0.173 & & & \\
0.261 & 0.1152 & 0.5 & 0.0576 \\
0.347 & & & \\
0.600 & & & \\
0.221 & & & \\
0.295 & 0.1354 & 0.5 & \\
0.347 & & & \\
0.600 & & & \\
0.200 & & 0.0677 \\
0.347 & & & \\
0.600 & & & \\
\hline
\end{tabular}

Table 2. Height $H$, width $W$ and hydraulic radius $R_{\mathrm{h}}$ of different conduits used to study the effects of conduit shape on tracer dispersion

\begin{tabular}{cccc}
\hline$v_{\text {in }}$ & $H$ & $W$ & $R_{\mathrm{h}}$ \\
$\mathrm{m} \mathrm{s}^{-1}$ & $\mathrm{~m}$ & $\mathrm{~m}$ & $\mathrm{~m}$ \\
\hline 0.3 & & 0.5 & 0.125 \\
0.3 & 0.5 & 1.0 & 0.100 \\
0.3 & 0.25 & 2.0 & 0.058 \\
0.3 & 0.125 & 4.0 & 0.031 \\
\hline
\end{tabular}

general, roughness enhances turbulence in the flow field and thereby affects tracer transport. Rectangular obstacles $(0.2 \times 0.2 \times 0.1 \mathrm{~m})$ were introduced at the bottom of the conduit to represent roughness of a typical glacial stream bed (Fig. 8a). In another scenario, the influence of the bottom roughness was increased by widening the conduit. To conserve the cross-sectional area, the ceiling was shaped asymmetrically (Fig. 8b). These situations were simulated using again $v_{\text {in }}=0.3 \mathrm{~m} \mathrm{~s}^{-1}$.

\section{a}

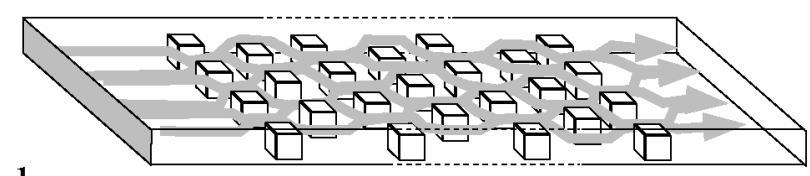

b

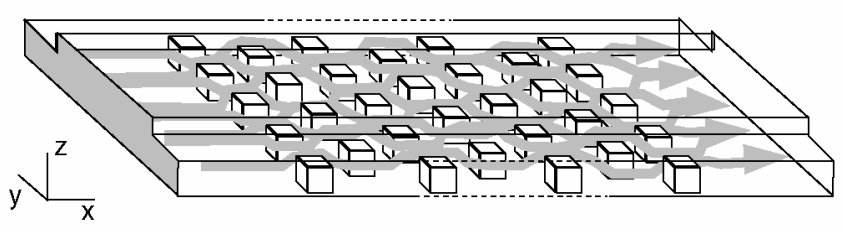

Fig. 8. Conduit geometries containing roughness elements. Apart from the obstacles, the conduit in (a) is identical with that shown in Figure 5. The asymmetrical shape of the conduit in (b) was introduced to enhance the influence of bottom roughness. Main water trajectories are indicated by arrows. 


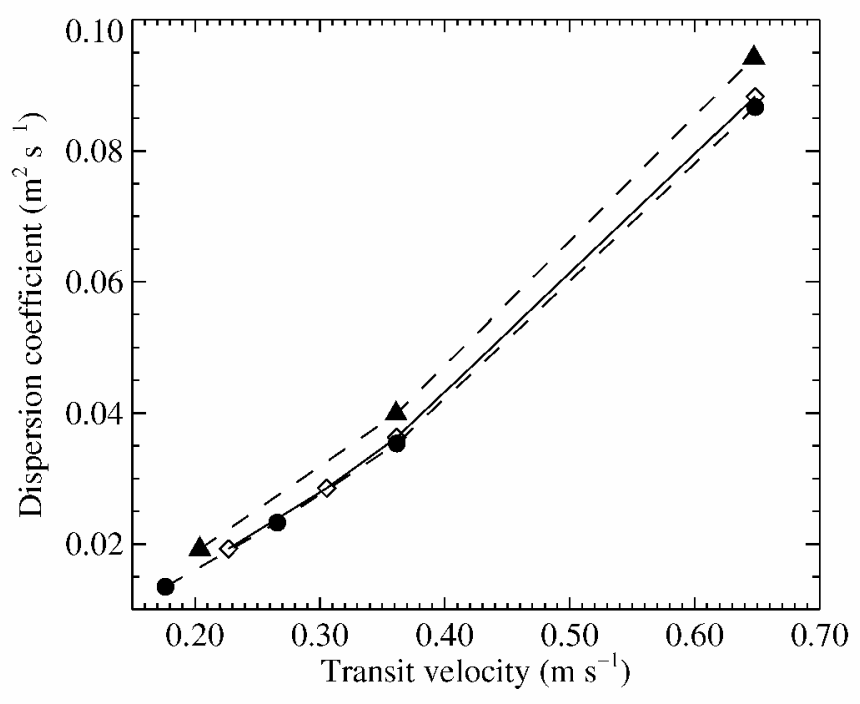

Fig. 9. Velocity-dispersion relationships for three conduits of different cross-sectional area. $A=0.0576 \mathrm{~m}^{2}$ for solid circles, $A=0.0677 \mathrm{~m}^{2}$ for open diamonds and $A=0.125 \mathrm{~m}^{2}$ for solid triangles.

\section{Model results}

Figure 9 shows $v-D$ relationships resulting from the 11 experiments performed to study the interdependence of tracer dispersion and cross-sectional area. The curves feature a positive relationship between $v$ and $D$, with the slope of the curves increasing towards higher velocities. The dependence of dispersion coefficients on cross-sectional area is displayed by several $v-D$ relationships obtained for different conduit sizes. We find that a larger conduit yields systematically higher dispersion coefficients than a smaller one.

Results from varying the hydraulic radius at constant flow velocity and constant cross-sectional area are shown in Figure 10. We can extrapolate the graph with two additional points. First, the trivial case $R_{\mathrm{h}}=0$ yields $D=0$. Second, we adopt a value determined by Hauns and others (2001) for a perfectly homogeneous velocity field. This condition is realized for an infinitely high and wide conduit. Therefore $R_{\mathrm{h}} \rightarrow \infty$ and it was found that $D_{\infty}=0.045$ $\mathrm{m}^{2} \mathrm{~s}^{-1}$ for $v=0.3 \mathrm{~m} \mathrm{~s}^{-1}$. Figure 10 demonstrates that with increasing hydraulic radius, dispersion approaches asymptotically $D_{\infty}$.

Table 3 lists the results of the three experiments performed to investigate the effect of roughness on tracer dispersion. Comparing the conduits with and without obstacles we find that introduction of roughness causes a substantial increase of the dispersion coefficient. When the influence of roughness is further increased as considered in the third scenario, $D$ increases even more, although the hydraulic radius of this conduit is smaller than those of the previous scenarios.

\section{GONGLUDING DISGUSSION}

The $v-D$ relationships derived from our tracer experiments at Unteraargletscher reveal pronounced anticlockwise hystereses. We suggested that the dynamic geometry of a Röthlisberger channel might be responsible for this behavior. To explain the hysteresis, we supposed a positive relationship between the dispersion coefficient $D$ and the cross-sectional area $A$ of the conduit. While the results of the numerical

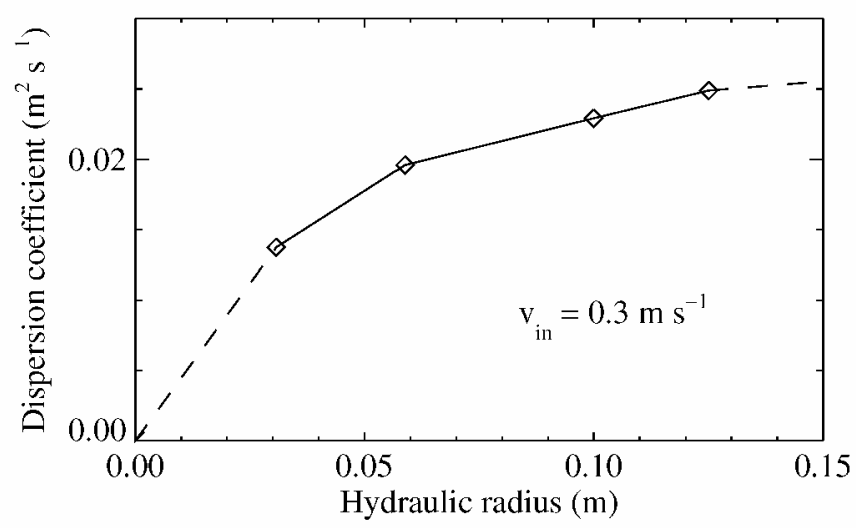

Fig. 10. Effect of hydraulic radius on dispersion. The flow velocity was kept constant in all scenarios. The dashed lines denote extrapolations of the relationship based on data from Hauns and others (2001). See text for details.

experiments shown in Figure 9 indicate such a relationship, the dependence is not very strong. In these experiments, the increase of $A$ was accomplished by increasing the height of a rectangular conduit of constant width, which involves a change of the perimeter and therefore the influence of the conduit walls. The influence of the conduit walls was expressed in terms of hydraulic radius $R_{\mathrm{h}}$. Figure 10 reveals that an increase of $R_{\mathrm{h}}$ at constant cross-sectional area also increases the dispersion coefficient. However, this effect is relevant only for hydraulic radii below the meter scale. Towards larger values of $R_{\mathrm{h}}$, the increase of $D$ is attenuated and $D$ approaches a maximum value. This indicates that the increase of $D$ in Figure 9 would also approach an upper limit since an increase of $A$ is accompanied by an increase of $R_{\mathrm{h}}$. The diameter of the subglacial conduit beneath Unteraargletscher is estimated to be on the order of meters (Schuler, 2002). On this scale, the effect of changes in conduit size on tracer dispersion would be very weak.

Based on these results, it is difficult to explain the $v-D$ hysteresis by a change of the conduit size alone. However, the dynamics of a Röthlisberger channel can account for the observed behavior if it is accompanied by a roughness change. It is shown by our numerical experiments that $D$ is strongly affected by changes in roughness such that increased roughness generates enhanced dispersion (Table 3). In our model we assumed constant size and roughness along a straight, rectangular conduit, which is certainly a strong simplification of the real flow path beneath Unteraargletscher. Instead, a subglacial conduit in nature might be curved and might exhibit variability in diameter and roughness along its length, thereby leading to significantly higher dispersion coefficients than those obtained from our numerical experiments. In addition, measurements of subglacial water pressure (e.g. Hubbard and

Table 3. Comparison of dispersion coefficients for three conduits of different roughness. Here, roughness is expressed as the ratio of the obstacle volume $V_{\mathrm{o}}$ to the water volume $V_{\mathrm{w}}$

\begin{tabular}{ccl}
\hline$R_{\mathrm{h}}$ & $V_{\mathrm{o}} / V_{\mathrm{w}}$ & \multicolumn{1}{c}{$\begin{array}{c} \\
\mathrm{m}^{2} \mathrm{~s}^{-1}\end{array}$} \\
$\mathrm{~m}$ & 0 & 0.01717 \\
\hline 0.0706 & 0.119 & 0.05906 \\
0.0706 & 0.156 & 0.09783 \\
0.0614 & & \\
\hline
\end{tabular}


others, 1995; Murray and Clarke, 1995) suggest that flow paths expand as water spreads out along the glacier bed in response to an increase in subglacial discharge. This in turn enhances the influence of the rough glacier bed. Thus, variations in discharge can directly lead to roughness changes as required by our interpretation. During the declining limb of a diurnal discharge variation, subglacial drainage is widespread and therefore more dispersed, whereas it is more confined and less dispersed during the rising limb.

\section{AGKNOWLEDGEMENTS}

The conduction of tracer tests over entire diurnal discharge cycles involved sleepless and cold nights on the glacier. The assistance of T. Khazaleh, J. Helbing and L. Mutter during our fieldwork is gratefully acknowledged. Moreover we thank M. Hauns for his model code and F. Hermann for support with the CFX software. Two anonymous reviewers made valuable suggestions to improve an earlier version of the manuscript. This study was partly funded by Eidgenössiche Technische Hochschule grant 0-20527-98. Swiss military helicopters provided logistic support in the field.

\section{REFERENGES}

Box, G. E. P., G. M. Jenkins and G. C. Reinsel. 1994. Time series analysis forecasting and control. Third edition. Englewood Cliffs, NJ, Prentice-Hall.

Collins, D. N. 1982. Flow-routing of meltwater in an alpine glacier as indicated by dye tracer tests. Beitr. Geol. Schweiz, Ser. Hydrol. 28, 523-534.

Fountain, A. G. 1993. Geometry and flow conditions of subglacial water at South Cascade Glacier, Washington State, U.S.A.; an analysis of tracer injections. 7. Glaciol., 39(131), 143-156.

Harlow, F. H. and P. I. Nakayama. 1967. Turbulence transport equations. Phys. Fluids, 10(11), 2323-2332.

Hauns, M. 1999. Modeling tracer and particle transport under turbulent flow conditions in karst conduit structures. (Ph.D. thesis, Université de Neuchâtel. Centre d'Hydrogéologie.)

Hauns, M., P.-Y. Jeannin and F. Hermann. 1998. Tracer transport in karst underground rivers: tailing effect from channel geometry. Bull. Hydrogéol., 16, $123-142$.
Hauns, M., P.-Y. Jeannin and O. Atteia. 2001. Dispersion, retardation and scale effect in tracer breakthrough curves in karst conduits. $\mathcal{F}$. Hydrol., 241(3), 177-193.

Hock, R. and R. LeB. Hooke. 1993. Evolution of the internal drainage system in the lower part of the ablation area of Storglaciären, Sweden. Geol. Soc. Am. Bull., 105(4), 537-546.

Hubbard, B. P., M. J. Sharp, I. C. Willis, M. K. Nielsen and C. C. Smart. 1995. Borehole water-level variations and the structure of the subglacial hydrological system of Haut Glacier d'Arolla, Valais, Switzerland. F. Glaciol., 41 (139), 572-583.

Kohler, J. 1995. Determining the extent of pressurized flow beneath Storglaciären, Sweden, using results of tracer experiments and measurements of input and output discharge. F. Glaciol., 41(138), 217-231.

Kreft, A. and A. Zuber. 1978. Physical meaning of the dispersion equation and its solutions for different initial and boundary conditions. Chem. Eng. Sci., 33(11), 1471-1480.

Launder, B.E. and D.B. Spalding. 1974. The numerical computation of turbulent flow. Comput. Methods Appl. Mech. Eng., 3 (2), 269-289.

Murray, T. and G. K. C. Clarke. 1995. Black-box modeling of the subglacial water system. F. Geophys. Res., 100 (B7), 10,231-10,245.

Nienow, P.W., M. J. Sharp and I. C. Willis. 1996. Velocity-discharge relationships derived from dye tracer experiments in glacial meltwaters: implications for subglacial flow conditions. Hydrol. Processes, 10, 1411-1426.

Röthlisberger, H. 1972. Water pressure in intra- and subglacial channels. $\mathcal{F}$. Glaciol., 11(62), 177-203.

Sauty, J.-P. and W. Kinzelbach. 1988. On the identiftcation of the parameters of groundwater mass transport. In Custodio, E., A. Gurgui and J. P. Ferreira, eds. Groundwater flow and quality modelling. Dordrecht, Reidel Publishing Company, 33-56.

Schuler, T. 2002. Investigation of water drainage through an alpine glacier by tracer experiments and numerical modeling. Eidg. Tech. Hochschule, Zürich. Versuchsanst. Wasserbau, Hydrol. Glaziol. Mitt. 177. (ETH Ph.D. thesis No. 14835.)

Seaberg, S. Z., J. Z. Seaberg, R. LeB. Hooke and D. W. Wiberg. 1988. Character of the englacial and subglacial drainage system in the lower part of the ablation area of Storglaciären, Sweden, as revealed by dye-trace studies. 7. Glaciol., 34(117), 217-227.

Spring, U. and K. Hutter. 1982. Conduit flow of a fluid through its solid phase and its application to intraglacial channel flow. Int. F. Eng. Sci., 20(2), 327-363.

Taylor, G. I. 1954. The dispersion of matter in turbulent flow through a pipe. Proc. R. Soc. London, Ser. A, 223(1155), 446-468.

Willis, I. C., M. J. Sharp and K. S. Richards. 1990. Configuration of the drainage system of Midtdalsbreen, Norway, as indicated by dye-tracing experiments. F. Glaciol., 36(122), 89-101. 